Slavica

bruxellensia

\section{Slavica bruxellensia}

Revue polyphonique de littérature, culture et histoire

slaves

$10 \mid 2014$

Espace slave, espace germanique

\title{
Traduction du récit « Pan » de Bruno Schulz
}

Traduction du polonais

\section{Alain van Crugten}

\section{(2) OpenEdition}

\section{Journals}

Édition électronique

URL : http://journals.openedition.org/slavica/1672

DOI : $10.4000 /$ slavica. 1672

ISSN : 2034-6395

Éditeur

Université libre de Bruxelles - ULB

Référence électronique

Alain van Crugten, «Traduction du récit «Pan » de Bruno Schulz », Slavica bruxellensia [En ligne],

10 | 2014, mis en ligne le 15 avril 2014, consulté le 19 avril 2019. URL : http://journals.openedition.org/ slavica/1672 ; DOI : 10.4000/slavica.1672

Ce document a été généré automatiquement le 19 avril 2019

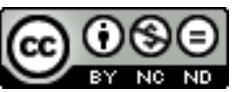

Les contenus de Slavica bruxellensia sont mis à disposition selon les termes de la Licence Creative Commons Attribution - Pas d'Utilisation Commerciale - Pas de Modification 3.0 France. 


\title{
Traduction du récit « Pan » de Bruno Schulz
}

Traduction du polonais

\author{
Alain van Crugten
}

\section{Présentation}

1 Alain Van Crugten est né à Bruxelles en 1936. Germaniste, slaviste, traducteur du polonais (Tadeusz Rożewicz, Sławomir Mrożek, Marian Pankowski, Stanisław Grochowiak), du néerlandais (e.a. Tom Lanoye et Joost Zwagerman), du tchèque (Karel Čapek), du russe (Aleksandr Zinoviev) et de l'anglais (e.a. Robert Nye, Luc Sante et John Tytell), il a reçu dernièrement le Prix des Phares du Nord 2013 pour sa traduction de La Langue de ma mère de l'auteur flamand Tom Lanoye. Romancier, on lui doit Des Fleuves impassibles (1997), Spa si beau! (1999), Korsakoff (2003, Prix Rossel des Jeunes), Bibardu (2005), Pourquoi pas moi? (2006) et Principessa (2008). Il a également écrit des recueils de nouvelles (Personnes déplacées [2001], Stef et autres fictions [2005]) et sept pièces de théâtre. Nous l'avions interviewé dans notre quatrième numéro ${ }^{1}$.

Il a dernièrement entrepris une nouvelle traduction de Sklepy cynamonowe (Les Boutiques de cannelle, 1933-1934²) de Bruno Schulz. L'œuvre majeure de cet écrivain polonais d'origine juive, né en Galicie polonaise sous l'empire austro-hongrois, présente le monde magique d'une petite bourgade aux confins du monde dans laquelle se mêlent des éléments réels et fantaisistes ainsi que diverses mythologies propres à l'Europe centrale et orientale. Schulz décrit la vie d'antan dans une langue incroyablement belle et envoûtante. Dans sa prose, véritable défi pour le traducteur, il dévoile ses talents de peintre et de conteur hors pair. Voici un extrait de cet ouvrage : le chapitre intitulé «Pan » 


\section{Traduction}

2 Dans un coin de la cour, derrière les baraques et annexes, il y avait comme une ruelle, un dernier embranchement enfermé entre la réserve, le cabinet et l'arrière du poulailler, unecrique perdue, sans issue.

C'était le cap le plus lointain, le Gibraltar de cette cour, qui se frappait désespérément la tête sur une palissade aveugle, la paroi ultime qui clôturait ce monde.

Sous ses planches couvertes de mousse coulait un filet d'eau noire et puante, une rigole de boue grasse et pourrissante qui ne séchait jamais ; c'était la seule route qui menait au monde à travers la frontière de la palissade. Mais le désespoir de cette petite impasse crasseuse avait cogné la tête durant si longtemps sur cet obstacle que l'une des fortes planches horizontales avait cédé. Nous, les garçons, avions fait le reste, nous avions enfoncé et arraché la lourde planche de ses piquets. Nous avions ainsi forcé une ouverture, une fenêtre sur le soleil. Debout sur la planche jetée comme un pont sur la flaque de boue, le prisonnier de la cour pouvait se glisser horizontalement par la fente, qui lui donnait accès à un monde nouveau, vaste et aéré. C'était un grand et vieux jardin retourné à l'état sauvage. Des groupes imposants de hauts poiriers et de pommiers à la large ramure poussaient là, entourés d'un murmure argenté, d'un filet bruissant de scintillements blancs. Une herbe dense, mêlée, jamais fauchée, couvrait le terrain ondulé d'un manteau duveteux. On y voyait d'ordinaires brins d'herbes des prairies surmontés de plumeaux et d'épis, mais aussi le délicat filigrane du persil sauvage et des carottes, les feuilles rudes et froissées des lierres, des orties blanches qui sentaient la menthe, des plantains brillants et durs, constellés de taches de rouille, d'où jaillissaient des grappes de gros grains rougeâtres. Tout cela, cette espèce d'édredon de plantes entremêlées, baignait dans une atmosphère douce, dans un vent bleuâtre saturé de ciel. Quand vous vous couchiez dans l'herbe, toute une géographie bleue de nuages et de continents dérivait audessus de vous et vous respiriez l'immense carte des cieux.Au contact de cet air, les feuilles et les pousses se couvraient de petits poils légers, une couche de duvet et de petits crochets aigus qui semblaient être là pour capter et retenir l'oxygène. Cette pellicule délicate et blanchâtre unissait les feuilles à l'atmosphère, leur donnait la luisance grisargent de vagues d'air, de méditations ombreuses entre deux éclats de soleil. L'une de ces plantes, jaune, ses tiges pâles pleines d'un suc lactescent, se gonflait d'air et ne distillait de ses pousses vides que de l'éther, rien qu'un nuage de petits globes de plumes laiteuses que le vent dispersait et qui se fondaient sans bruit dans le silence azuré.

Le jardin était vaste, il se divisait en plusieurs branches et connaissait diverses zones et divers climats. D'un côté il était ouvert, plein du lait du ciel et de l'air, et il étendait sous le firmament la plus molle, la plus délicate, la plus duveteuse des verdures. Mais à mesure qu'on s'enfonçait dans le deuxième embranchement, il était plongé dans l'ombre entre l'arrière d'une ancienne fabrique d'eau gazeuse et le mur déglingué d'une grange, il s'obscurcissait à vue d'œil, devenait inamical et négligé, il se laissait aller à la sauvagerie, se hérissait d'orties et de chardons, se couvrait d'une gale végétale, puis, au fin fond, dans le grand rectangle formé par les murs, il perdait toute mesure et laissait éclater sa folie. Là, ce n'était plus un jardin, mais un paroxysme de démence, une éruption de rage, une débauche éhontée et cynique. Les choux vides des grandes bardanes s'étalaient en donnant bestialement libre cours à leur furie - énormes sorcières qui se dépouillaient de leurs larges jupes en plein jour, les rejetaient, jupe après jupe, jusqu'à ce que ces haillons 
gonflés, bruissants et troués, ces guenilles de plantes enterrent sous elles toute cette race bâtarde et querelleuse. Mais les jupes avides recommençaient à se gonfler et à s'étendre, elles se repoussaient et se recouvraient mutuellement, elles se multipliaient et s'enflaient en une masse de couches feuillues jusqu'au bord du toit de la grange.

C'est à cet endroit que je l'ai vu pour la première et unique fois de ma vie, dans la touffeur abrutissante de l'heure méridienne. C'était un de ces instants où le temps, ivre et furieux, s'arrache à la routine des événements et court à grands cris à travers les champs comme un vagabond en fuite. Perdant le contrôle, l'été s'épanouit sans mesure et sans raison dans l'espace tout entier, croît en tous lieux dans un élan sauvage, se dédouble, se détriple, entre dans un temps autre, dégénéré, dans une dimension inconnue, une démence.

C'était l'heure où j'étais gagné par la manie de la chasse aux papillons, la passion de poursuivre ces petites taches tremblotantes, ces petits flocons blancs errants qui voletaient en zigzag dans l'air brûlant. Un jour donc, l'une des petites taches brillantes se divisa en plein vol, d'abord en deux, puis en trois, et ce triangle blanc, frémissant et miroitant, m'entraîna comme un feu follet à travers la luxuriance des chardons qui cuisaient au soleil.

Je m'arrêtai en arrivant à la limite des bardanes, n'osant m'enfoncer dans ce coin perdu. Soudain je l'aperçus.

Il était accroupi devant moi, plongé jusqu'aux aisselles dans les bardanes.

Je vis ses larges épaules dans une chemise sale et les lambeaux crasseux d'une veste. Il restait là, ramassé sur lui-même, comme prêt à bondir, son dos semblant ployer sous un poids énorme. Tout son corps respirait lourdement sous l'effort et la sueur coulait sur son visage cuivré qui luisait au soleil. Il ne bougeait pas, il avait l'air d'être occupé à quelque rude labeur, d'affronter sans un mouvement une charge gigantesque.

Je restai cloué au sol, comme pris dans une tenaille par son regard.

C'était le visage d'un vagabond ou d'un ivrogne. Une touffe de cheveux sales se dressait sur son front, qu'il avait large et bombé comme un galet roulé par une rivière. Mais ce front était barré de rides profondes. Je ne savais si c'était la douleur ou la brûlure du soleil ou un effort surhumain qui distordait ainsi sa face et en crispait les traits jusqu'à l'éclatement. Ses yeux noirs s'enfoncèrent dans les miens avec l'intensité du désespoir ou de la souffrance extrême. Ces yeux me regardaient et ne me regardaient pas, me voyaient et ne me voyaient pas. C'étaient des boules prêtes à exploser, tendues par l'exaltation suprême de la torture ou par la violente volupté de l'extase.

Et soudain, ces traits contractés à se rompre se déformèrent en une grimace affreuse, déchirée, suppliciée, et cette grimace s'élargit, prit la même expression de délire ou d'extase que les yeux, s'enfla, se convulsa de plus en plus, puis se brisa dans un éclat de rire pareil à une toux rauque.

Paralysé par la stupéfaction, je le vis, la poitrine puissante secouée par un hurlement de rire, se redresser lentement de sa position accroupie. Courbé comme un gorille, les mains soutenant son pantalon qui pendait en guenilles, il prit la fuite à grands bonds, se frayant un chemin dans la masse ondulante des bardanes - un Pan sans flûte qui se réfugiait en panique dans ses forêts sacrées originelles. 


\section{NOTES}

1. Voir: Dufour A. \& Vandenborre K., «Entretien avec Alain van Crugten », in: Slavica bruxellensia[En ligne], 4|2009, mis en ligne le 15 octobre 2009. URL: http:// slavica.revues.org/256; DOI : 10.4000/slavica.256

2. La version française de cet ouvrage est une compilation de traductions effectuées par trois traducteurs différents (Thérèse Douchy, Georges Sidre et Jerzy Lisowski). Schulz Br., Les Boutiques de cannelle, Gallimard, coll. « 'L'Imaginaire », Paris, 2005, 210 p.

INDEX

Mots-clés : littérature polonaise

Index chronologique : entre-deux-guerres, XXe siècle

Index géographique : Galicie, Pologne

oeuvretraite Schulz B. : Sklepy cynamonowe (Les Boutiques de cannelle) 